\title{
Three-dimensional reduction method with a modified C2 isthmus screw in irreducible atlantoaxial dislocation: a technical note
}

\author{
Shengyuan Zhou ${ }^{1}$, Bo Yuan ${ }^{1}$, Weicong Liu ${ }^{2}$ Yifan Tang ${ }^{1}$, Xiongsheng Chen ${ }^{1 *}$ and Lianshun Jia ${ }^{1}$
}

\begin{abstract}
Background: Three-dimensional reduction plays a vital role in surgical reduction of irreversible atlantoaxial dislocation (IAAD). However, the most commonly used combination of $\mathrm{C} 1$ pedicle screw (PS) or lateral mass screw (LMS) and C2 PS or isthmus screw often fails to achieve satisfactory reduction at one time. The difficulty is usually caused by short anteroposterior and vertical distance between heads of C1 and C2 screws, which lack enough space for reduction operation. The objective of this study is to describe a three-dimensional reduction method with a modified C2 isthmus screw and to illustrate its advantage and effectiveness for IAAD.

Methods: Twelve patients with IAAD underwent reduction and fixation with modified C2 isthmus screw combined with C1 PS or LMS, fusion with autologous bone graft. The insertion point was lateral to the intersection of caudal edge of C2 lamina and lateral mass, with a trajectory towards C2 isthmus, via lateral mass. The three-dimensional reduction was achieved through pulling and distracting. Radiographic evaluation included anteroposterior and direct distance between different insertion points, the occipitoaxial angle (O-C2A), clivus-canal angle (CCA) and cervicomedullary angle (CMA). Clinical outcomes evaluation included the Japanese Orthopaedic Association (JOA) score, Visual analog scale (VAS) and Neck Disability Index (NDI).
\end{abstract}

Results: All the patients maintained effective reduction during the follow-up. The anteroposterior and direct distance was significantly higher in modified C2 isthmus screw than C2 PS whether combined with C1 PS or LMS $(P<0.05)$. The degree of O-C2A, CCA and CMA, JOA score, NDI, and VAS were significantly improved after the surgery $(\mathrm{P}<0.05)$.

Conclusions: Three-dimensional reduction method with a modified C2 isthmus screw is effective and safe in managing IAAD. It can increase the anteroposterior and vertical distance between the heads of $\mathrm{C} 1$ and $\mathrm{C} 2$ screws, which is benefit for the three-dimensional reduction operation of IAAD.

Keywords: Atlantoaxial dislocation, Screw, Reduction, Fixation

\section{Introduction}

Cervical spinal cord compression caused by atlanto-axial dislocation (AAD) often leads to paralysis, even threaten the life of patients. The anatomical reduction is the key

\footnotetext{
*Correspondence: cxspine@smmu.edu.cn

1 Spine Center, Department of Orthopedics, Shanghai Changzheng Hospital, Naval Medical University (Second Military Medical University), Shanghai 200003, People's Republic of China

Full list of author information is available at the end of the article
}

to relieve spinal cord compression. Reasons for AAD mainly include transverse ligament rupture, old odontoid fracture, Os odontoideum, rheumatoid arthritis, and atlantoaxial developmental deformities. AAD could be manifested as simple or complex dislocation in sagittal, coronal or transverse plane [1-4]. The dislocation in sagittal plane could be anteroposterior, vertical and angulated. For coronal and transverse plane, the dislocation is usually shown as atlantoaxial joint space asymmetry and

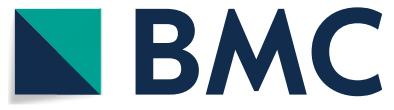

(c) The Author(s) 2021. Open Access This article is licensed under a Creative Commons Attribution 4.0 International License, which permits use, sharing, adaptation, distribution and reproduction in any medium or format, as long as you give appropriate credit to the original author(s) and the source, provide a link to the Creative Commons licence, and indicate if changes were made. The images or other third party material in this article are included in the article's Creative Commons licence, unless indicated otherwise in a credit line to the material. If material is not included in the article's Creative Commons licence and your intended use is not permitted by statutory regulation or exceeds the permitted use, you will need to obtain permission directly from the copyright holder. To view a copy of this licence, visit http://creativecommons.org/licenses/by/4.0/. The Creative Commons Public Domain Dedication waiver (http://creativeco mmons.org/publicdomain/zero/1.0/) applies to the data made available in this article, unless otherwise stated in a credit line to the data. 
rotatory dislocation respectively [5]. Spinal canal stenosis caused by anteroposterior AAD and compression on the cervical spinal cord or medulla oblongata caused by vertical dislocation of odontoid are the main causes of spinal cord compression. Therefore, the reduction of atlantoaxial joint in anteroposterior and vertical direction is the key of decompression.

In terms of the severity and difficulty in the reduction of the atlantoaxial joint, the dislocation is usually divided into reducible, irreducible and fixed AAD [6, 7]. For reducible dislocation, stabilization can be achieved by the screw-rod system, screw-hook system or cable tension band after reduction. For irreducible dislocation, the reduction of the atlantoaxial joint in three planes should be taken into consideration. The reduction would be failed if only anteroposterior AAD was paid attention without the correction of vertical and angulated dislocation. Vertical and angulated reduction are the same keys to success. So, the three-dimensional reduction plays a vital role in surgical reduction. However, at present, the most commonly used combination of $\mathrm{C} 1$ pedicle screw (PS) or lateral mass screw (LMS) and C2 PS or isthmus screw in the posterior approach often fails to achieve satisfactory reduction at one time. Multiple-adjustment of the depth between $\mathrm{C} 1$ and $\mathrm{C} 2$ screws [8], or rotation of rods, or lever mechanism is needed for reduction $[9,10]$. The main surgical methods for irreversible atlantoaxial dislocation (IAAD) include anterior release and reduction with posterior fusion $[11,12]$, posterior occipitoaxial fusion [13], transoral atlantoaxial anterior decompression and fusion [15-17], etc.

The difficulty of reduction of IAAD was caused by the following two reasons: (1) the anteroposterior distance between heads of $\mathrm{C} 1$ and $\mathrm{C} 2$ screws is too short to draw the $\mathrm{C} 1$ posteriorly (Fig. 1a); (2) the vertical distance between heads of $\mathrm{C} 1$ and $\mathrm{C} 2$ screws is too short to manipulate the vertical distraction (Fig. 1b). Therefore, to increase the anteroposterior and vertical distance between the heads of $\mathrm{C} 1$ and $\mathrm{C} 2$ screws is the key to achieve atlantoaxial reduction. In our clinical practice, we modified $\mathrm{C} 2$ isthmus screw and set the insertion point at the intersection of caudal edge of $\mathrm{C} 2$ lamina and lateral mass, with a trajectory towards $\mathrm{C} 2$ isthmus, via lateral mass. The insertion point is to increase the anteroposterior and vertical distance between the heads of $\mathrm{C} 1$ and $\mathrm{C} 2$ screws, which is benefit for the reduction of anteroposterior and vertical dislocation (Fig. 1c, d). The modified $\mathrm{C} 2$ isthmus screw is different from the other techniques reported in the literature, such as Magerl screw [18] and short isthmus (par) screw [19, 20] (Fig. 2).

The objective of this study is to describe a three-dimensional reduction method with a modified $\mathrm{C} 2$ isthmus screw and to illustrate its advantage and effectiveness for
IAAD. No studies to date have reported the details and outcomes on this technique.

\section{Methods \\ Patient population}

Twelve patients diagnosed as IAAD (6 males and 6 females) with a mean age of 43.8 years (range 13-66 years) were included in this study. All the patients underwent $\mathrm{CT}$ angiography to study the anomalous course of vertebral artery. The inclusion criteria included (1) patients with IAAD who cannot achieve complete reduction after skull traction; (2) cross-section of $\mathrm{C} 2$ isthmus was suitable for insertion of screw (width $>35 \mathrm{~mm}$; height $>35 \mathrm{~mm}$ ). Patients with vertebral artery variation (e.g. high riding vertebral artery) and severe osteoporosis, as well as patients unable to tolerate surgery, were excluded. The type of IAAD included Os odontoideum in 5 , rheumatoid arthritis in 3 , fracture nonunion in 2 , fracture malunion in 1 , and developmental malformation in 1. All procedures performed in studies involving human participants were in accordance with the 1964 Helsinki Declaration and its later amendments or comparable ethical standards. Informed consent was approved by the Institutional Review Board, and all subjects gave informed consent.

\section{Preoperative traction}

All the patients underwent skull traction under the electrocardiograph monitoring before the surgery. The skull traction was applied with a beginning of $3 \mathrm{~kg}$ and gradually adjusted to $10 \mathrm{~kg}(1 \mathrm{~kg}$ every $24 \mathrm{~h})$ if the patients did not manifest as dyspnea or decline of muscle strength. The traction direction is perpendicular to the anteriorposterior diameter of atlas, and is adjusted from flexion (Fig. 3a) to extension (Fig. 3b) position gradually to loosen the structure which affecting reduction. The partial reduction was obtained in 11 cases while no reduction was achieved in one patient with malunion after fracture. The loosen of skull screw may occur and should be paid attention during the traction.

\section{Modified C2 isthmus screw}

The entry point was the intersection of caudal edge of C2 lamina and lateral mass. The trajectory is in cephalad direction towards the $\mathrm{C} 2$ isthmus, via lateral mass (Fig. 4a). The anterior wall of C2 lamina and superior articular surface of $\mathrm{C} 2$ should not be injured or perforated (Fig. 4b).

\section{Reduction technique of AAD}

The reduction of anteroposterior, vertical and angulated dislocation on the sagittal plane is essential to the three-dimensional reduction of AAD. Reduction 


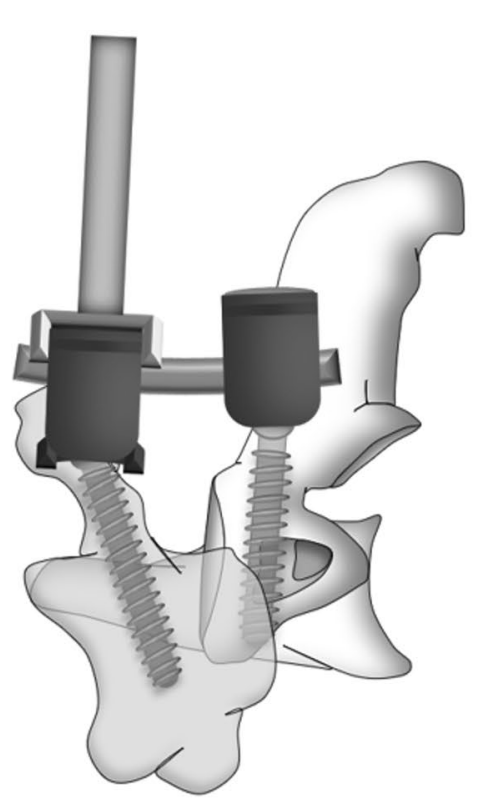

a

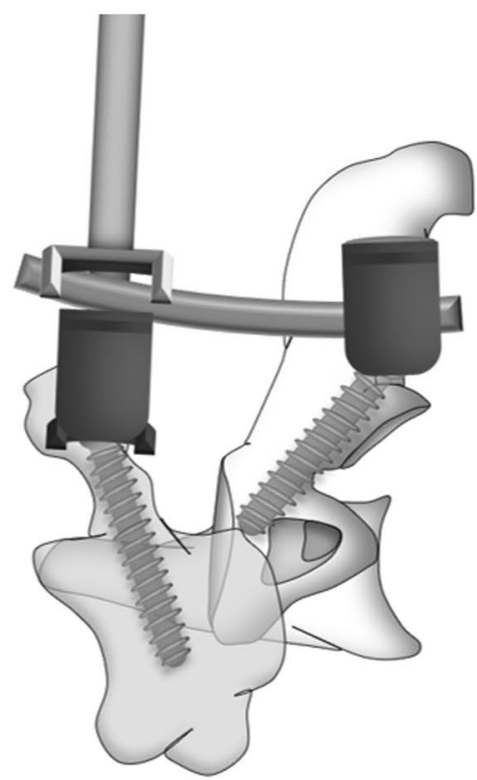

C

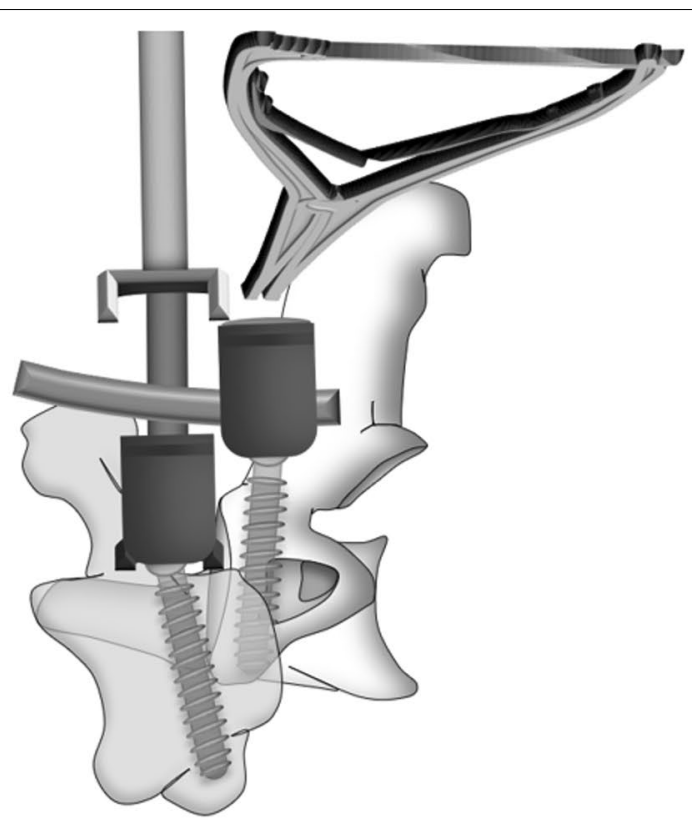

b

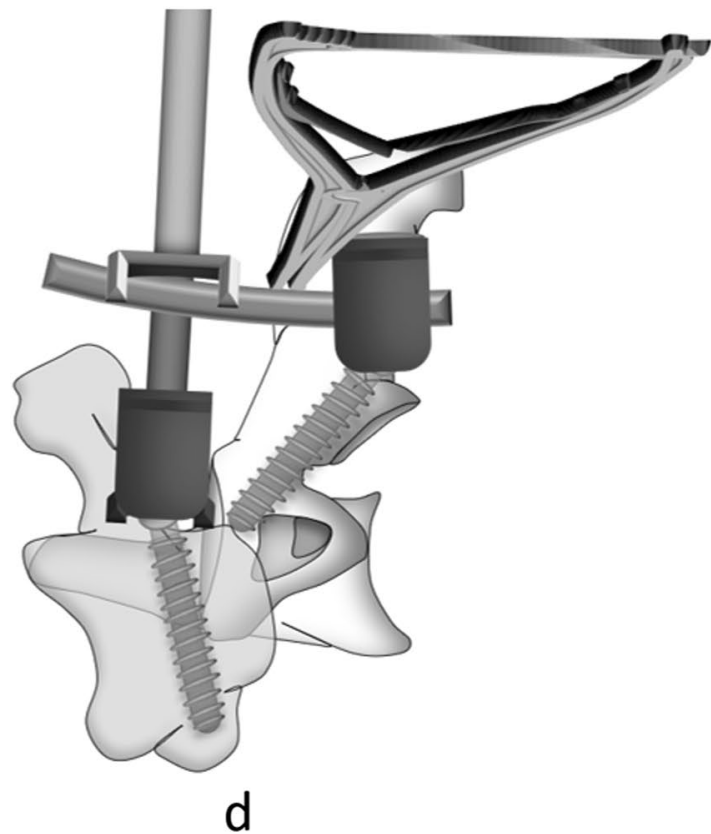

Fig. 1 a C1 PS and C2 PS, with anteroposterior distance is too short to draw the C1 posteriorly. b C1 LMS and C2 PS, with vertical distance is too short to manipulate reduction for the vertical distraction. C-d C1 PS or LMS combined with modified C2 isthmus screw, with anteroposterior and vertical distance are both increased, which is benefit for the reduction. LMS lateral mass screw; PS pedicle screw

process: (1) Insert of C1 PS or LMS and modified C2 isthmus screw (Fig. 5i); (2) Fasten the pre-bent rod to modified C2 isthmus screw (Fig. 5ii); (3) Pull the C1 and partially correct anterior-posterior and angulated dislocation (Fig. 5iii); (4) Vertically distract and keep bilateral side of atlantoaxial joint symmetrical (Fig. 5iv); (5) Achieve the reduction of anteroposterior, vertical and angulated dislocation, and complete lateral and rotational dislocations simultaneously (Fig. 5v); (6) Fix the rod over screw heads (Fig. 5vi). 


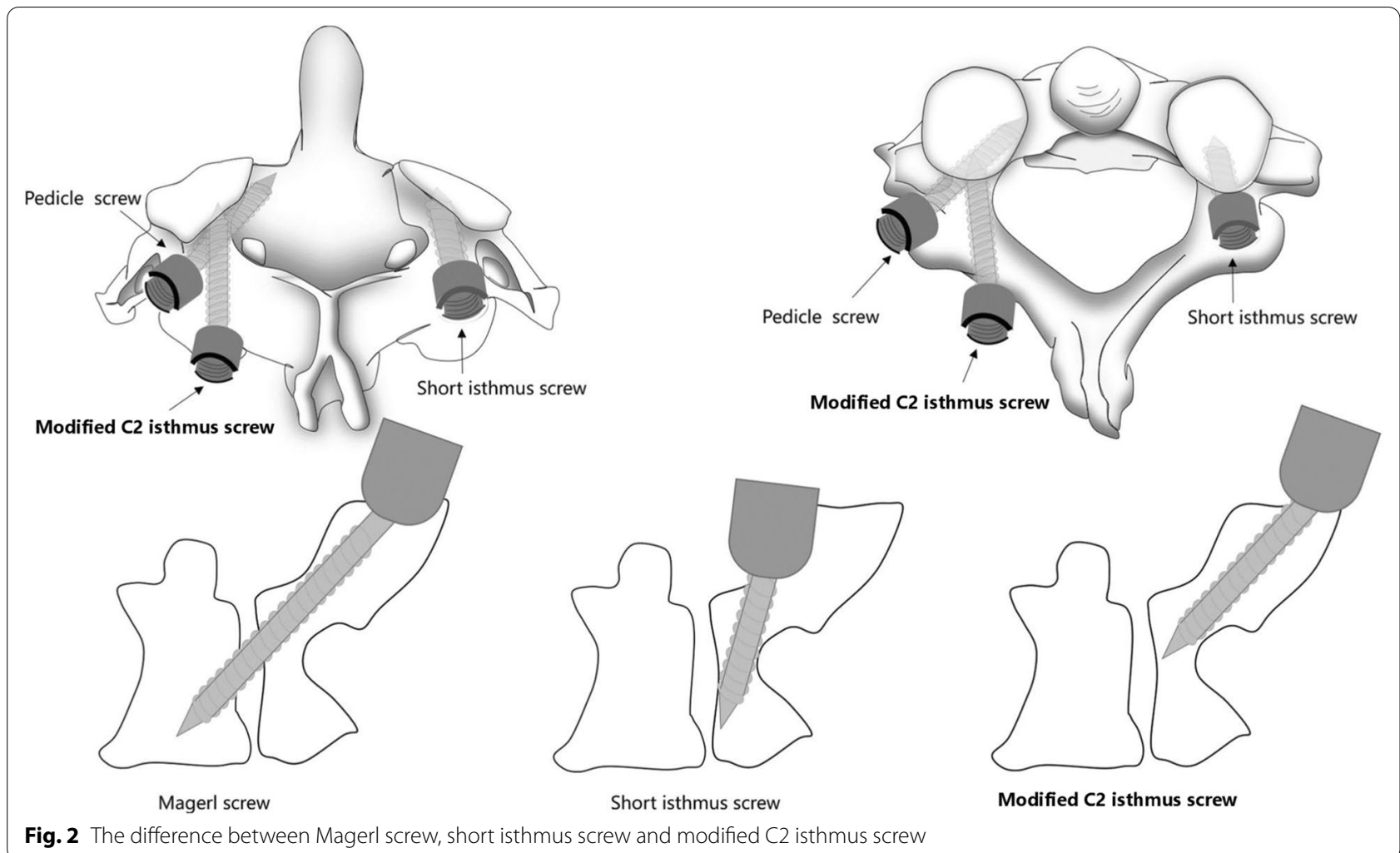

Fig. 2 The difference between Magerl screw, short isthmus screw and modified C2 isthmus screw

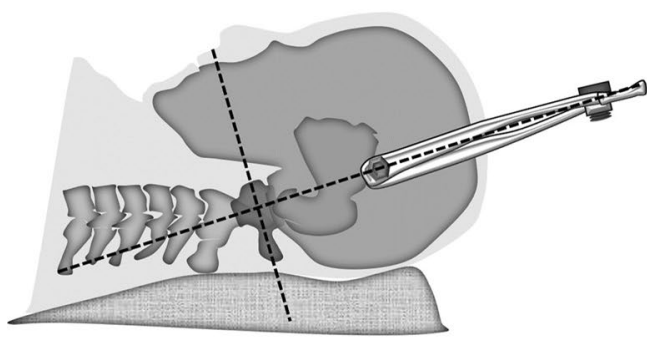

a

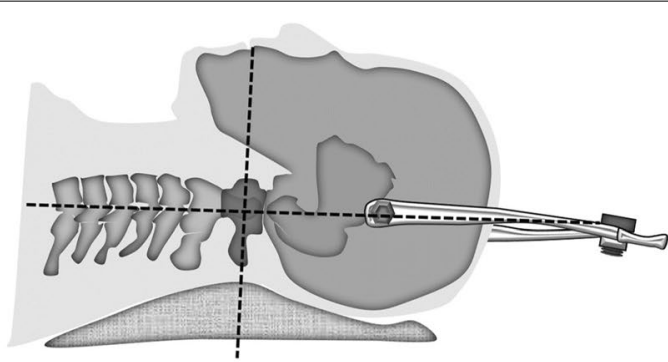

$b$

Fig. 3 Traction direction is perpendicular to the anterior-posterior diameter of atlas. a Flexion position traction, $\mathbf{b}$ extension position traction

\section{Outcome evaluation}

The anteroposterior and direct distance between heads of $\mathrm{C} 1$ and $\mathrm{C} 2$ screws have vital influence on pulling and distracting during the reduction. The anteroposterior and direct distance between the insertion point of $\mathrm{C} 1$ LMS or PS and C2 PS or modified C2 isthmus screw were measured on preoperative lateral X-ray by PACS system (AGFA, Mortsel, Belgium). On the lateral X-ray films, we set the insertion of C1 LMS at the junction of the posterior arch and lateral mass of C1; C1 PS at the junction of the posterior arch and posterior tubercle of C1; C2 PS at the junction of the isthmus and superior margin of lamina of C2; modified C2 isthmus screw at the junction of the inferior articular process and inferior margin of lamina of C2 (Fig. 6). The distance was used to reflect the operation space in the different combination of $\mathrm{C} 1$ and $\mathrm{C} 2$ screws during the reduction process.

The occipitoaxial angle (O-C2A), clivus-canal angle (CCA) and cervicomedullary angle (CMA) were measured to evaluate the reductive effect after surgery. The $\mathrm{O}-\mathrm{C} 2 \mathrm{~A}$ defined by the angle between McGregor line and the line tangential to the inferior aspect of the axis [21] (Fig. 7A). CCA was defined as the angle between the line of inferior $1 / 3$ clivus and the line extending from 


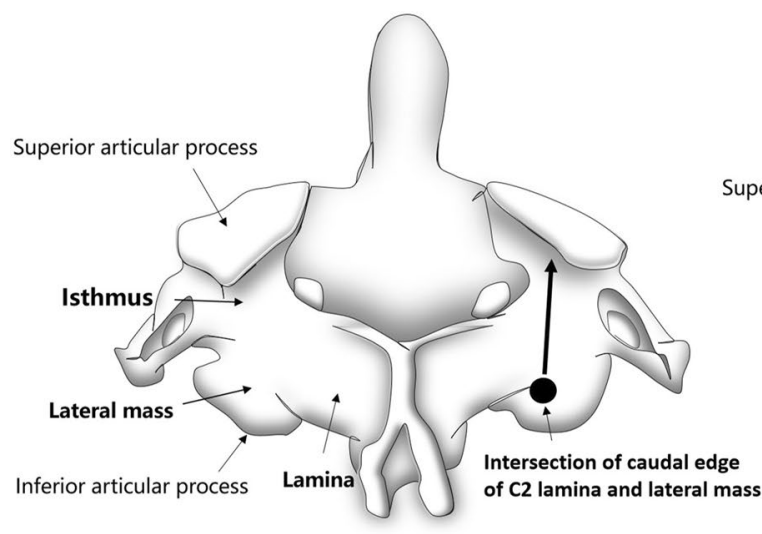

a

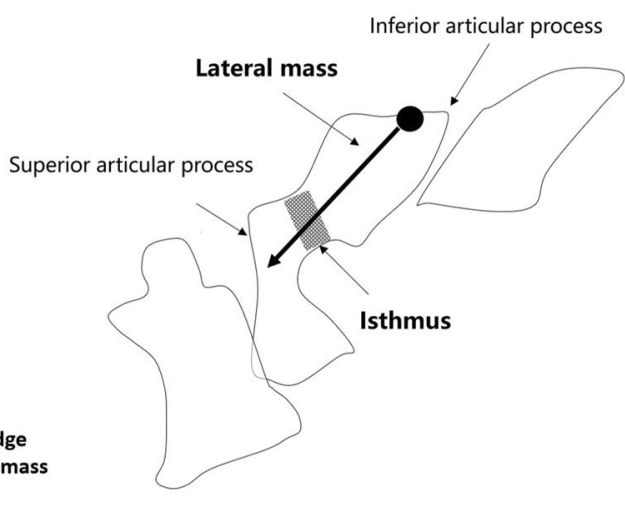

b

Fig. 4 Insertion points of modified C2 isthmus screw. a Convergent direction, b cephalad direction

the posterior border of the dens to the posterior-inferior border of the axis body on the midline sagittal CT reconstruction images [22] (Fig. 7b). CMA was defined as the angle between the line extending the anterior border of the ventral medulla and the line extending the anterior border of the ventral upper cervical spinal cord on the midline sagittal T2 MRI [23] (Fig. 7C).

Clinical and radiographic data were obtained before and after surgery, and last follow-up. Clinical outcome assessment included the Japanese orthopedics association (JOA) score for neurological statue, Visual analog scale (VAS) for neck pain and neck disability index (NDI). Radiological examinations were performed before and after the surgery regularly to analyze the reduction and fusion. Bone fusion was defined as bridging bone across the bone graft interface on plain radiographs or CT scan.

\section{Statistically analysis}

Paired t test was used to compare the difference. Statistical analysis was performed using SPSS version 16.0 (SPSS Inc., Chicago, IL). Significance was defined as $\mathrm{P}<0.05$.

\section{Results}

\section{Surgical process}

All the patients underwent reduction and fixation with C1 PS or LMS combined with modified C2 isthmus screw, fusion with autologous iliac bone graft. The C1-2 joints were not opened up in the surgery. For the patient with malunion after fracture nonunion, one-stage surgery including anterior osteotomy of odontoid through submandibular approach and posterior fixation C1 PS combined with modified $\mathrm{C} 2$ isthmus screw. The mean operation time was $132 \mathrm{~min}$ (range from 120 to $240 \mathrm{~min}$ ), and the mean intraoperative bleeding loss was $168 \mathrm{ml}$ (range from 100 to $600 \mathrm{ml}$ ).

\section{Radiological measurement}

Preoperative measurement results of average anteroposterior and direct distance between the insertion point of C1 PS or LMS and C2 PS or modified C2 isthmus screw were shown in Table 1 . The average distance was significantly higher in modified $\mathrm{C} 2$ isthmus screw group than C2 PS group whether combined with C1 PS or LMS (d1 $5.6 \mathrm{~mm}$ vs. d3 $12.5 \mathrm{~mm}$ and d2 $13.8 \mathrm{~mm}$ vs. $\mathrm{d} 420.7 \mathrm{~mm}$ in anteroposterior distance, $\mathrm{h} 120.7 \mathrm{~mm}$ vs. h3 $35.7 \mathrm{~mm}$ and h2 $21.1 \mathrm{~mm}$ vs. h4 $35.7 \mathrm{~mm}$ in direct distance, $\mathrm{P}<0.05)$.

Radiographic measurement results before and after surgery were shown in Table 2 . The mean degree of $\mathrm{O}-\mathrm{C} 2 \mathrm{~A}, \mathrm{CCA}$ and CMA before the surgery were $8.2^{\circ}$, $138.1^{\circ}, 142^{\circ}$, respectively. The mean degree of $\mathrm{O}-\mathrm{C} 2 \mathrm{~A}$, CCA and CMA after the surgery were $18.1^{\circ}, 148.7^{\circ}$, $155.2^{\circ}$, respectively, with significantly difference from pre-operative value $(\mathrm{P}<0.05)$.

\section{Functional outcomes}

The mean duration of follow-up was 62.2 months (range from 12 to 95 months). The atlantodental interval (ADI) is less than $3 \mathrm{~mm}$ on lateral X-ray and the compression on spinal cord have been released on MRI scan. All the patients showed clinical improvement in JOA (pre-op $10.4 \pm 2.8$, last follow-up $15.1 \pm 1.3$ ), VAS (pre-op 3.4 \pm 1.6 , last follow-up $1.5 \pm 0.8$ ) and NDI (pre-op $24 \% \pm 12.3 \%$, last follow-up 9.4\% $\pm 4.3 \%$ ) $(\mathrm{P}<0.05)$ and returned to normal work. All patients fused with iliac bone autograft achieved fusion. Autologous bone was used in 2 cases and absorbed during the follow-up. But no hardware failure occurred at the final follow-up. 


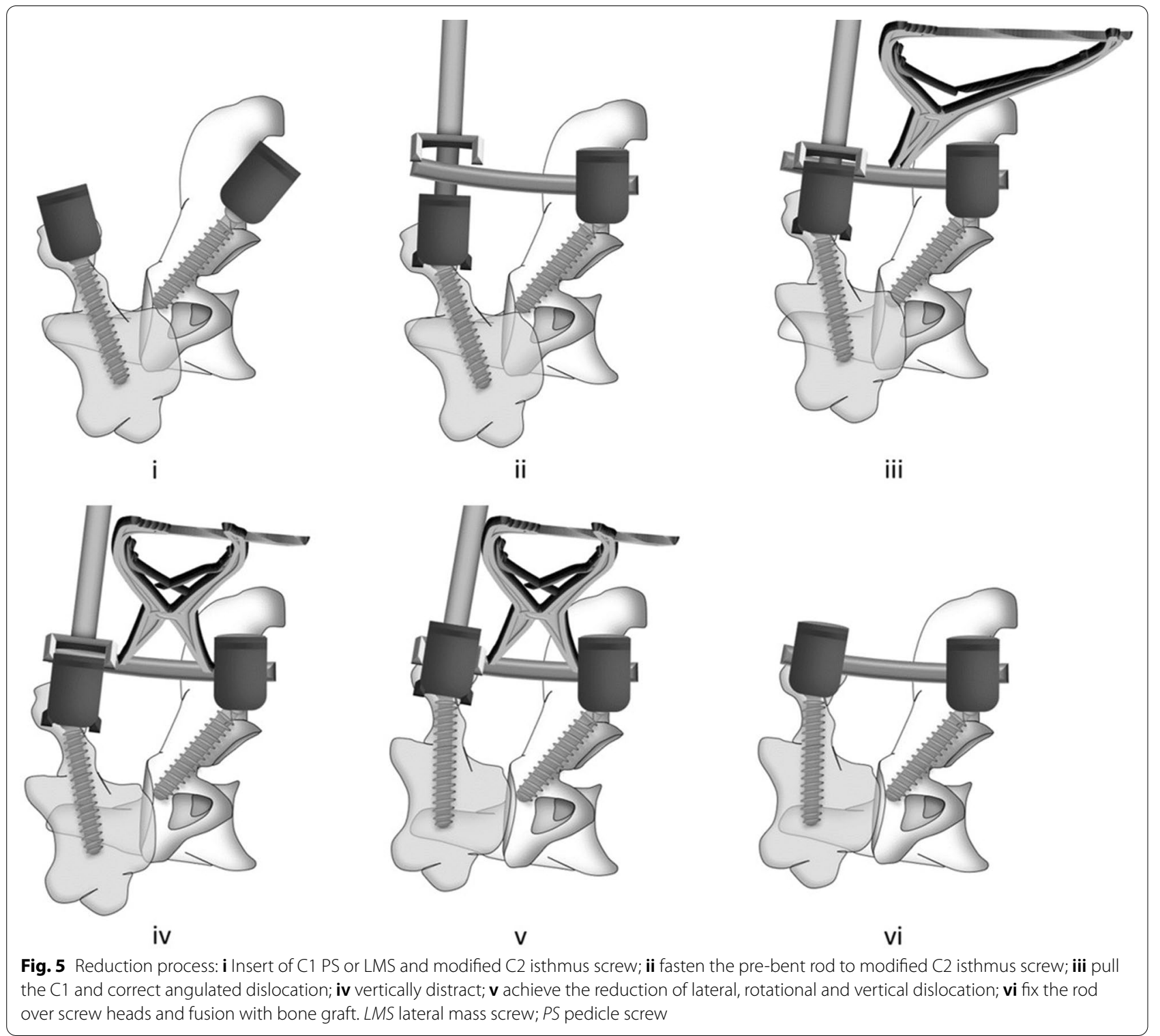

\section{Typical cases}

Two typical cases were shown in Figs. 8 and 9.

\section{Discussion}

The difficulty of the reduction of AAD is related to the atlantoaxial structure and the dislocation degree, as well as and the characteristics of the ventral tissue of atlantoaxial joint. For fixed AAD, it is essential for anterior odontoid osteotomy, release of atlantoaxial joint and removal of scars and osteophytes in atlantoodontoid joint. The reducibility in most patients with congenital deformities is determined by the obliquity of joints. Salunke et al. described a technique of comprehensive drilling of $\mathrm{C} 1-2$ joints through a posterior approach to release them helps to achieve single stage reduction thereby circumventing the anterior procedure [24]. When there is no bony structure hinders the reduction, C1 PS or LMS combined with modified $\mathrm{C} 2$ isthmus screw could achieve reduction by vertically distracting between $\mathrm{C} 1$ and $\mathrm{C} 2$, and pulling $\mathrm{C} 1$ posteriorly. Anterior release of atlantoaxial joint is not necessary for this kind of patients. In our study, all the patients with IAAD got reduction after singlestage surgery by using C1 PS or LMS combined with modified $\mathrm{C} 2$ isthmus screw. The $\mathrm{C} 1$ posterior arch and the C2 lamina are fused with autologous iliac bone grafts after reduction. For patients without stenosis of 


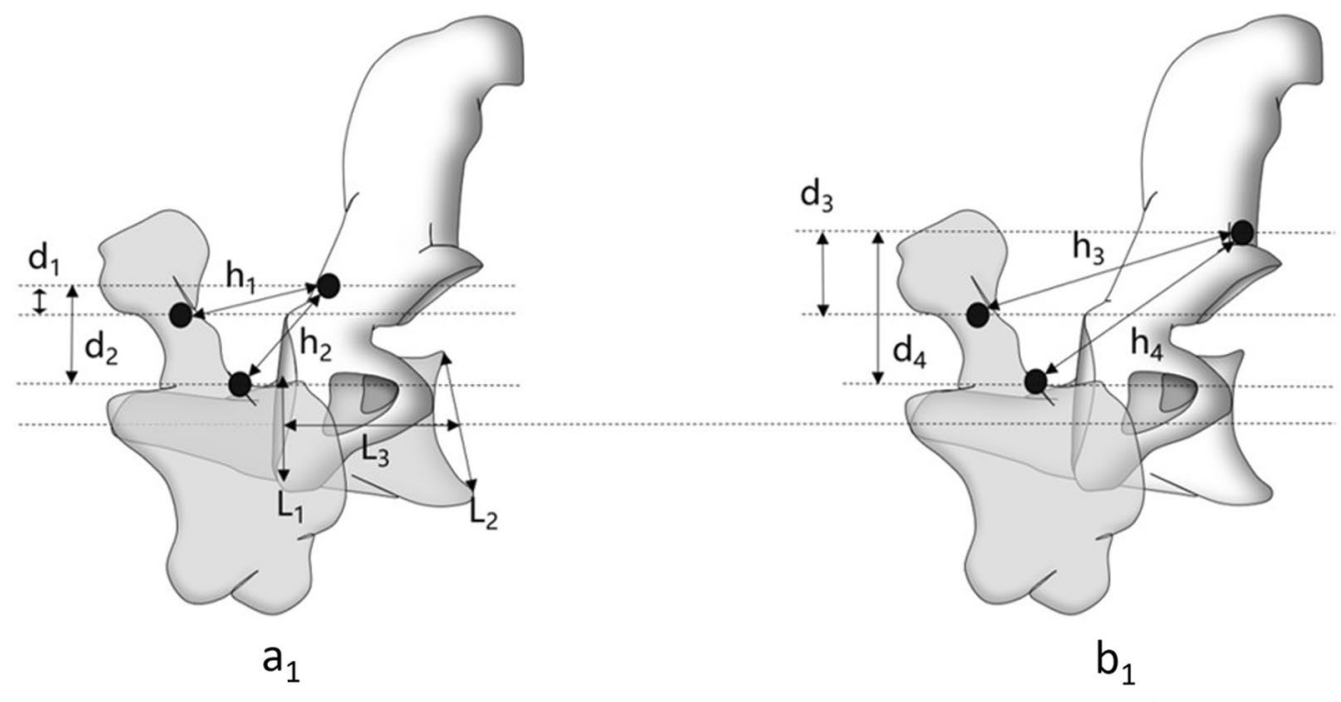

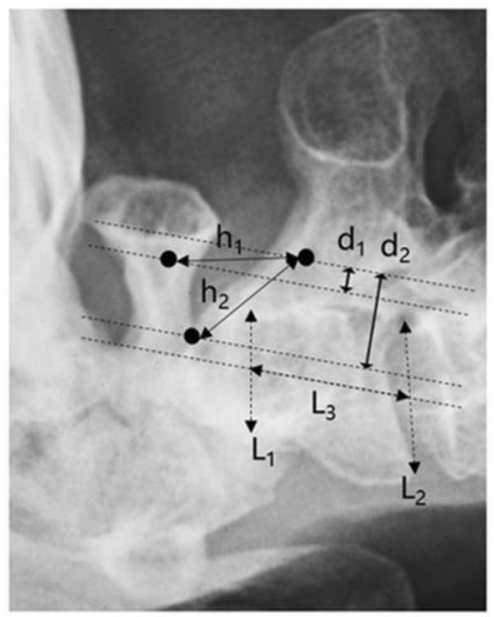

$a_{2}$

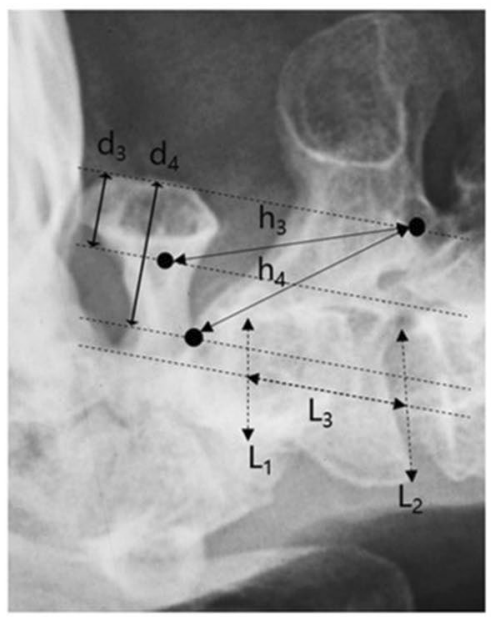

$b_{2}$

Fig. 6 Measurement of the distance between insertion point of C1 and C2 screws. a1 C1 PS or LMS combined with C2 PS on simulation diagram. b1 C1 PS or LMS combined with modified C2 isthmus screw on simulation diagram. a2 C1 PS or LMS combined with C2 PS on lateral X-ray. b2 C1 PS or LMS combined with modified C2 isthmus screw on lateral X-ray. L1 indicates the base of odontoid process; L2 indicates inferior margin of C2; $L 3$ indicates the line connecting the midpoint of $L 1$ and $L 2$. The measurement lines of HD are parallel to $L 3$. APD and DD of C1 PS and C2 PS are $\mathrm{d} 1$ and $\mathrm{h} 1 ; \mathrm{APD}$ and DD of C1 LMS and C2 PS are $\mathrm{d} 2$ and h2; APD and DD of C1 PS and modified C2 isthmus screw are d3 and h3; APD and DD of C1 LMS and modified C2 isthmus screw are $d 4$ and h4; with results showed $d 3>d 1, d 4>d 2, h 3>h 1$, h4 $>h 2$, which offer more operation space for reduction. $L M S$, lateral mass screw; PS pedicle screw; APD anteroposterior distance; DD direct distance

vertebral canal caused by congenital anomalies of $\mathrm{C} 1$, there is no need to remove the $\mathrm{C} 1$ posterior arch for decompression. Odontoid osteotomy through submandibular approach, followed by posterior reduction and fixation with C1 PS or LMS and modified C2 isthmus screw was performed on the patient with malunion after fracture. No dysphagia or bucking was found after the surgery. No vertebral artery injury occurred in any patient. The O-C2A, CCA and CMA improvement showed that dislocations on anteroposterior and vertical planes achieved complete reduction, the neurological function improved s20nsion load than short isthmus screw. The intralaminar screw is usually used as remedial measures after the failure of other screws, rather than the first choice. Magerl screw provides sufficient resistance to flexion-extension load and is suitable for the fixation in atlantoaxial instability or dislocation after reduction, instead of reduction in IAAD [25]. Base on Magerl technique, modified C2 isthmus screw set the entry point at the intersection of caudal 


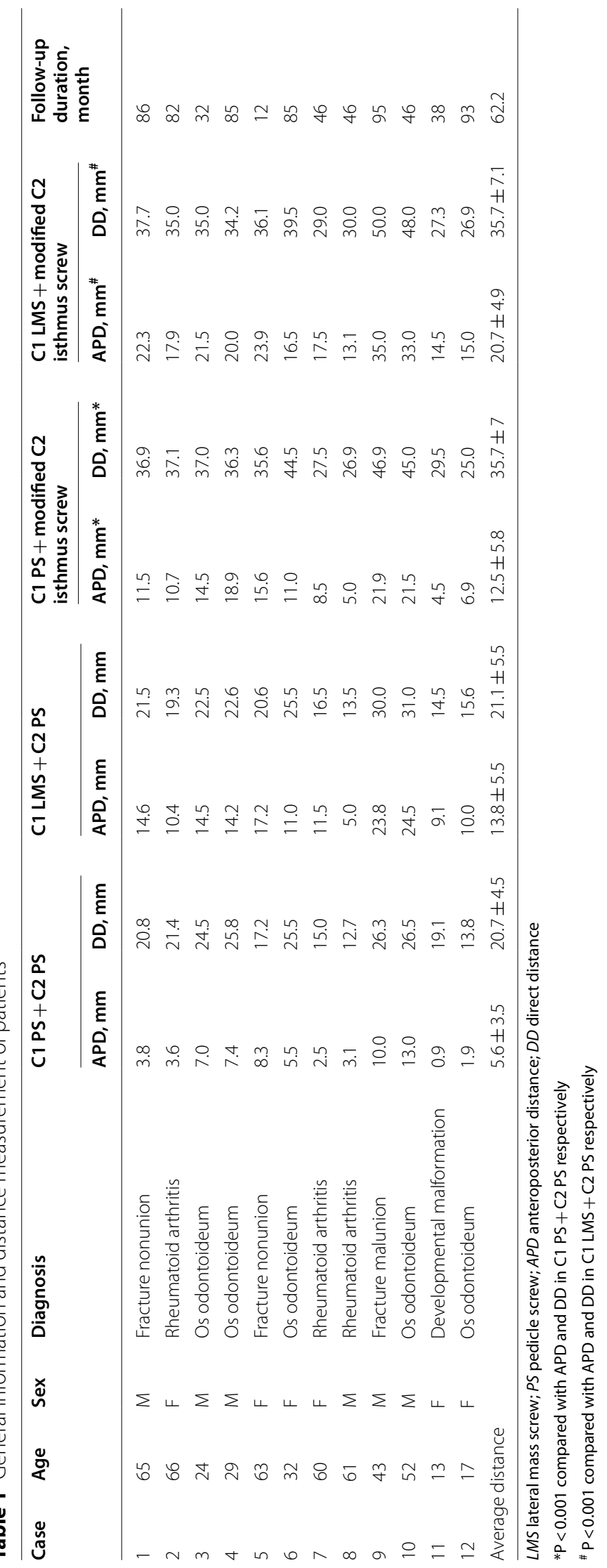




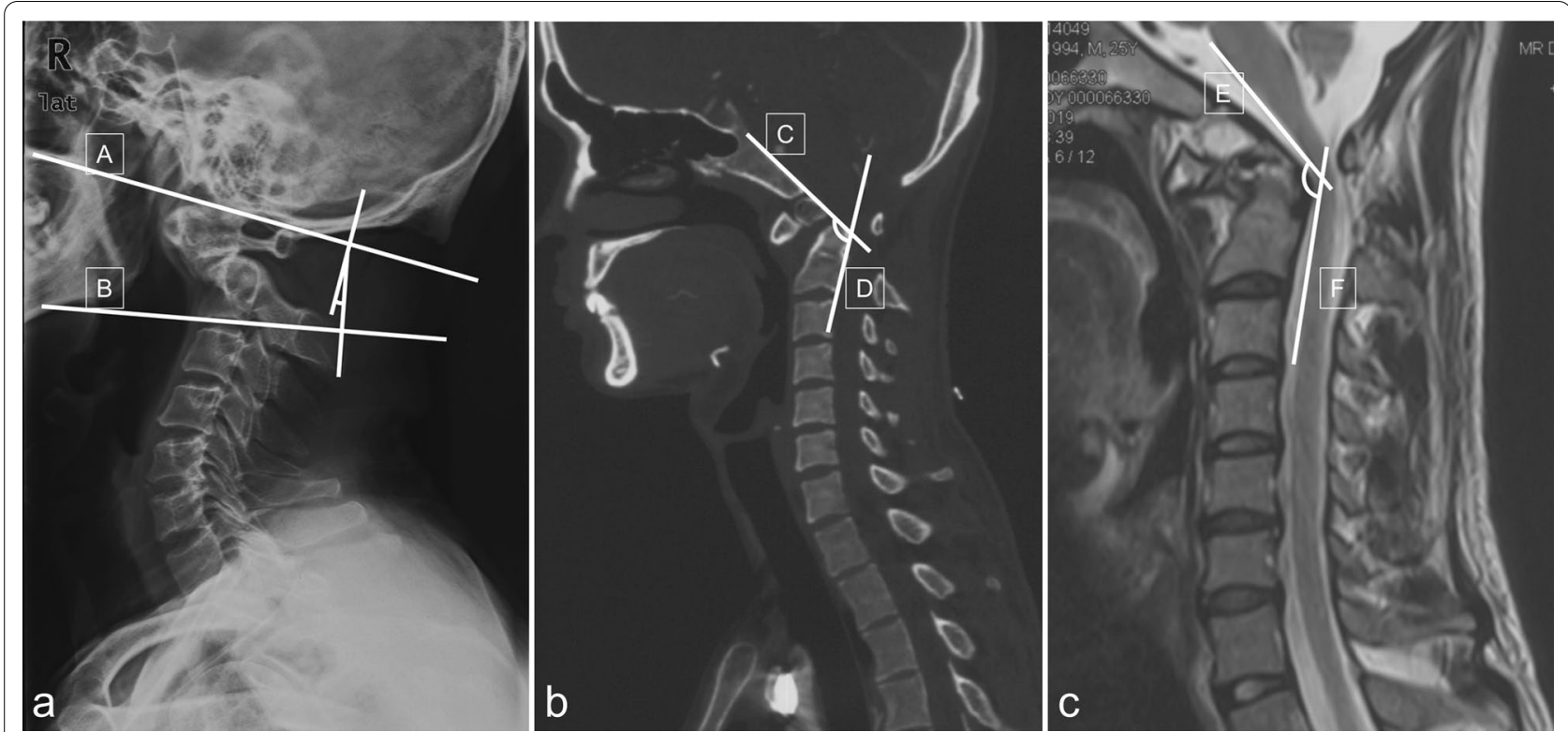

Fig. 7 Measurement of the O-C2A, CCA and CMA. a O-C2A: Angle between McGregor line (A line) and the line (B line) tangential to the inferior aspect of the axis. $\mathbf{b}$ CCA: Angle of the line of inferior 1/3 clivus (line $C$ ) and the line extending from the posterior border of the dens to the posteriorinferior border of the axis body (line D). c CMA: Angle of the line extending the anterior border of the ventral medulla (line E) and the line extending the anterior border of the ventral upper cervical spinal cord (line F) in midline sagittal T2 MRI. O-C2A, Occipitoaxial angle; CCA, clivus-canal angle; CMA, cervicomedullary angle

Table 2 Radiographic measurement before and after surgery

\begin{tabular}{|c|c|c|c|c|c|c|c|c|c|}
\hline \multirow[t]{2}{*}{ Case } & \multirow[t]{2}{*}{ Age } & \multirow[t]{2}{*}{ Sex } & \multirow[t]{2}{*}{ Diagnosis } & \multicolumn{2}{|l|}{$\mathrm{OC} 2 \mathrm{~A}$} & \multicolumn{2}{|l|}{ CCA } & \multicolumn{2}{|l|}{ CMA } \\
\hline & & & & Pre-op, degree* & $\begin{array}{l}\text { Post-op, } \\
\text { degree* }^{*}\end{array}$ & $\begin{array}{l}\text { Pre-op, } \\
\text { degree }^{\#}\end{array}$ & $\begin{array}{l}\text { Post-op, } \\
\text { degree }\end{array}$ & $\begin{array}{l}\text { Pre-op, } \\
\text { degree }^{\&}\end{array}$ & Post-op, degree ${ }^{\&}$ \\
\hline 1 & 65 & $M$ & $\begin{array}{l}\text { Fracture non- } \\
\quad \text { union }\end{array}$ & 15.9 & 8.5 & 123.5 & 145.4 & 147.9 & 158.9 \\
\hline 2 & 66 & $\mathrm{~F}$ & $\begin{array}{l}\text { Rheumatoid } \\
\text { arthritis }\end{array}$ & 21.3 & 22.6 & 146.6 & 150 & 147 & 152 \\
\hline 3 & 24 & $M$ & Os odontoideum & -11.3 & 24.8 & 111.6 & 145.5 & 120.9 & 156.5 \\
\hline 4 & 29 & $M$ & Os odontoideum & -10.2 & 4.8 & 109.5 & 119.5 & 124.4 & 139.5 \\
\hline 5 & 63 & $\mathrm{~F}$ & $\begin{array}{l}\text { Fracture non- } \\
\quad \text { union }\end{array}$ & -4.6 & 11.1 & 143.3 & 158.2 & 146.1 & 153.1 \\
\hline 6 & 32 & $\mathrm{~F}$ & Os odontoideum & -3.8 & 16.6 & 126.5 & 136.5 & 143.9 & 154.2 \\
\hline 7 & 60 & $\mathrm{~F}$ & $\begin{array}{l}\text { Rheumatoid } \\
\text { arthritis }\end{array}$ & 17.3 & 20 & 152.3 & 156.2 & 147.4 & 150.2 \\
\hline 8 & 61 & $M$ & $\begin{array}{l}\text { Rheumatoid } \\
\text { arthritis }\end{array}$ & 28.4 & 26.9 & 155.9 & 171.3 & 152.3 & 166.7 \\
\hline 9 & 43 & $M$ & $\begin{array}{l}\text { Fracture mal- } \\
\quad \text { union }\end{array}$ & 1.8 & 14.6 & 145.9 & 150.4 & 144.8 & 163.3 \\
\hline 10 & 52 & $M$ & Os odontoideum & 10 & 18.3 & 151.3 & 158.5 & 143.6 & 150.2 \\
\hline 11 & 13 & $\mathrm{~F}$ & $\begin{array}{l}\text { Developmental } \\
\text { malformation }\end{array}$ & 9.9 & 16.9 & 144 & 151.2 & 129 & 164.7 \\
\hline 12 & 17 & $\mathrm{~F}$ & Os odontoideum & 24 & 31.5 & 146.5 & 142.1 & 156.8 & 152.6 \\
\hline \multicolumn{4}{|c|}{ Mean degree } & $8.2 \pm 13.7$ & $18.1 \pm 7.7$ & $138.1 \pm 16$ & $148.7 \pm 12.9$ & $142 \pm 11.2$ & $155.2 \pm 7.5$ \\
\hline
\end{tabular}

OC2A O-C2 angle; CCA clivus-canal angle; CMA cervicomedullary angle

${ }^{*} \mathrm{P}<0.005$ compared with pre-op OC2A

${ }^{\#} \mathrm{P}<0.005$ compared with pre-op CCA

\# $\mathrm{P}<0.005$ compared with pre-op CMA 

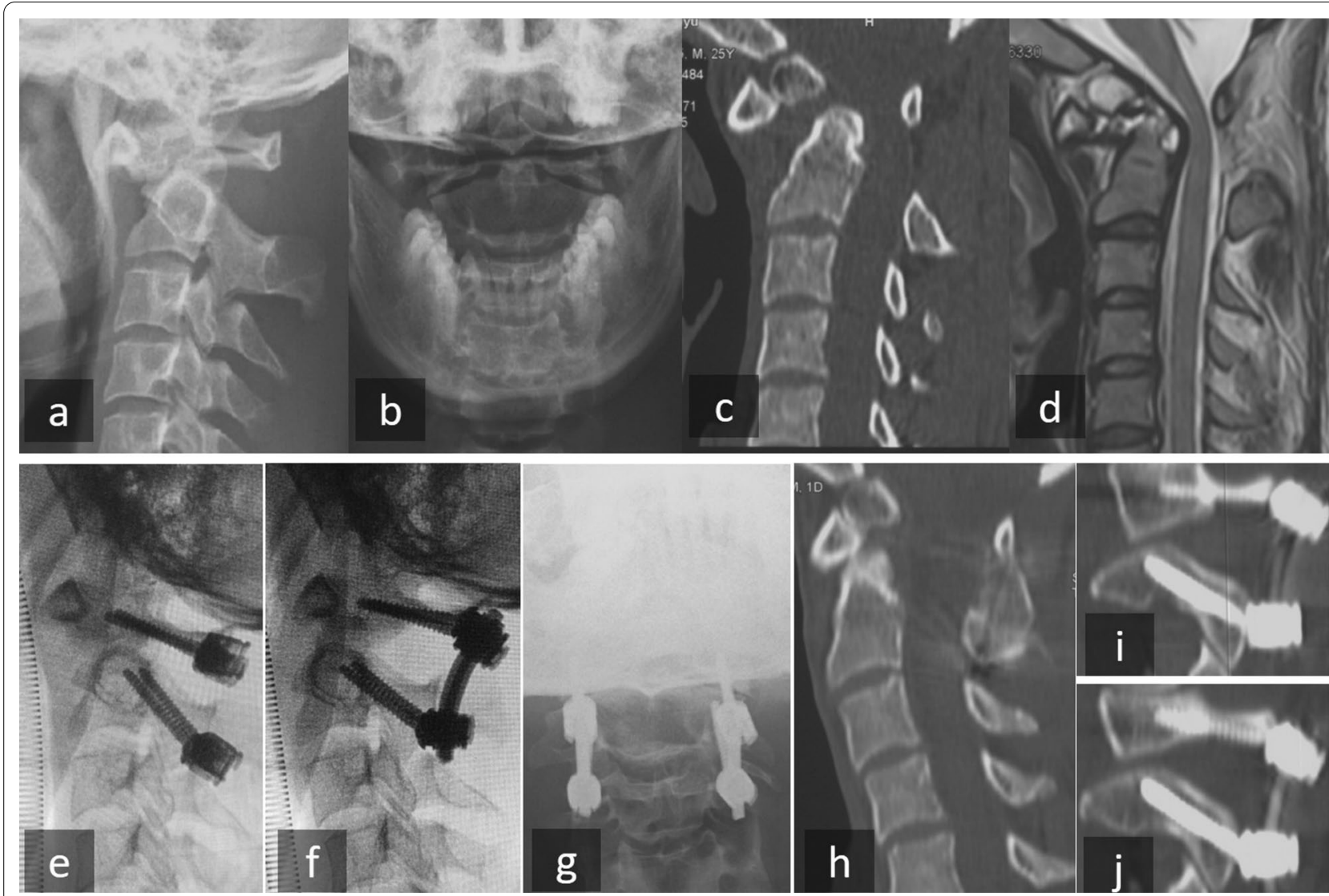

Fig. 8 A 24-year-old man with Os odontoideum. a-c Preoperative X-ray and CT scan showed Os odontoideum and atlantoaxial dislocation. d Preoperative MRI showed spinal cord compression. e Intraoperative X-ray showed the position of C1 PS combined with modified C2 isthmus screw and $\mathbf{f}$ reduction. $\mathbf{g}$ Postoperative anterior-posterior X-ray, and $\mathbf{h}$-j Postoperative CT scan showed good reduction and position of modified C2 isthmus screw. PS pedicle screw

edge of C2 lamina and lateral mass, the trajectory is via lateral mass and towards the $\mathrm{C} 2$ isthmus, without perforating the facet joint of $\mathrm{C} 1-2$. The anteroposterior and vertical distance between the heads of $\mathrm{C} 1$ and $\mathrm{C} 2$ screws were increased, which is beneficial to the reduction of IADD. Up to now, there has no related biomechanical research about modified C2 isthmus screw, but its trajectory is similar with Magerl screw and short isthmus screw, which can resist flexion-extension load effectively. The trajectory of modified C2 isthmus screw is shorter than that of Magerl screw while longer than that of short isthmus screw. We speculate that its resistance to flexion-extension load falls in between the above two screws, which needs further confirmation. In our study, no hardware failure occurred at the final follow-up, which reflected that the modified C2 isthmus screw could provide sufficient biomechanical properties for the reduction and maintenance.

Same as C2 PS, the insertion of modified C2 isthmus screw is affected by the anatomical structure of $\mathrm{C} 2$ isthmus [26]. The normal $\mathrm{C} 2$ isthmus width and height is about 7-8 $\mathrm{mm}$, which is enough for the placement of a $3.5 \mathrm{~mm}$ screw [27]. High riding vertebral artery is not rare in atlantoaxial dislocation patients $[28,29]$. For this kind of patient, C2 transverse foramen often moves towards the medial and superior location, even occupies a large part of the isthmus. It is not enough for the screw when the isthmus is narrow. Trans isthmic screws are not suitable for such patients because the insertion may injure the vertebral artery. Therefore, the presence of narrow isthmus and a high riding vertebral artery is a contraindication for the $\mathrm{C} 2$ modified isthmus screw. However, the artery can be mobilized and a C2 subfacetal screw can be inserted for this issue [30]. Preoperative computerized tomography angiography for the vertebral artery and three-dimensional reconstruction of the cervical spine is indispensable. The evaluation of the relationship between the vertebral artery and $\mathrm{C} 2$ isthmus and measurement of $\mathrm{C} 2$ isthmus width and height is helpful to avoid vertebral artery injury. 

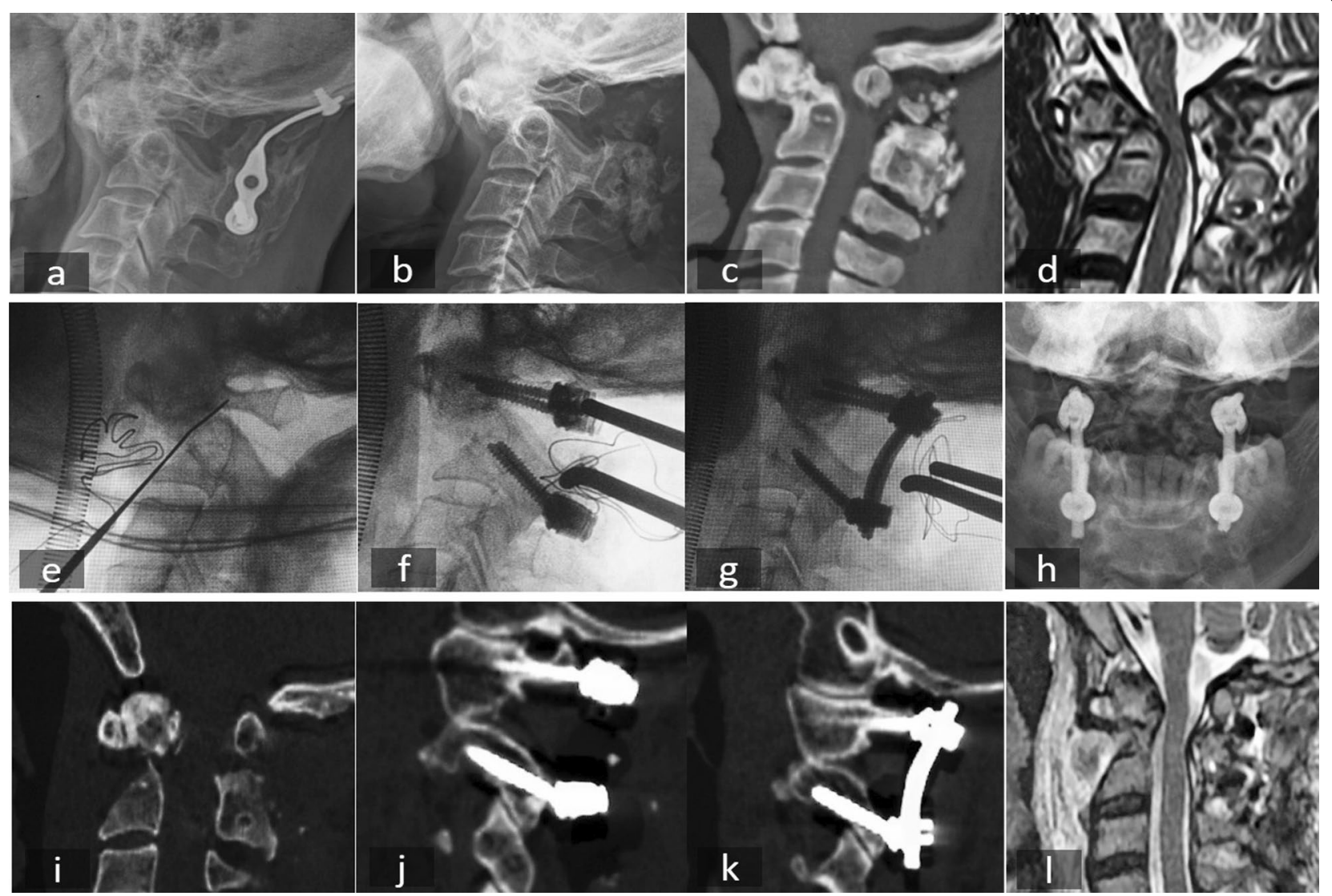

Fig. 9 A 43-year-old man with fracture of C2 combined with atlantoaxial dislocation. a Preoperative X-ray showed C0-C2 bone graft and fusion was performed due to fracture malunion and dislocation of C1-C2 19 years ago. b, c Preoperative $X$-ray and CT scan showed malunion of C2 fracture. $\mathbf{d}$ Preoperative MRI showed atlantoaxial dislocation and spinal cord compression. e Intraoperative X-ray showed anterior release and osteotomy of odontoid. $\mathbf{f}$ Intraoperative X-ray showed the position of C1 PS combined with modified C2 isthmus screw land $\mathbf{g}$ Reduction. $\mathbf{h}$ Postoperative anterior-posterior X-ray, and $\mathbf{i}-\mathbf{k}$ postoperative CT scan imagines showed good reduction and position of modified C2 isthmus screw. I Postoperative MRI showed the decompression of spinal cord. PS pedicle screw

\section{Conclusions}

Three-dimensional reduction method with a modified $\mathrm{C} 2$ isthmus screw is effective and safe in managing IAAD. Modified C2 isthmus screw made some modifications on the basis of Magerl screw and short isthmus screw. It can increase the anteroposterior and vertical distance between the heads of $\mathrm{C} 1$ and $\mathrm{C} 2$ screws, which is benefit for the three-dimensional reduction operation of AAD shown as anteroposterior, vertical, and angulated dislocation in the sagittal plane, especially for irreducible cases.

\section{Acknowledgements}

Not applicable.

\section{Authors' contributions}

SYZ and BY wrote the main manuscript text; WCL and YFT prepared all the figures; XSC designed the whole study; XSC and LSJ revised the manuscript. SYZ, BY and WCL were joint first authors. All authors reviewed the manuscript.
Funding

Not applicable.

\section{Availability of data and materials}

The datasets used during the current study available from the corresponding author on reasonable request.

\section{Declarations}

\section{Ethics approval and consent to participate}

All procedures performed in studies involving human participants were in accordance with the 1964 Helsinki declaration and its later amendments or comparable ethical standards. The experimental protocol was approved by the Shanghai Changzheng Hospital Institutional Review Board (2020SL015), and all subjects gave informed consent.

\section{Consent for publication}

All subjects gave consent to publish their data.

\section{Competing interest}

The authors declare that they have no conflict of interest. 


\section{Author details}

'Spine Center, Department of Orthopedics, Shanghai Changzheng Hospital, Naval Medical University (Second Military Medical University), Shanghai 200003, People's Republic of China. ${ }^{2}$ Department of Orthopedics, the Second Affiliated Hospital, Hunan Normal University, Changsha, People's Republic of China.

Received: 17 May 2021 Accepted: 25 July 2021

Published online: 12 August 2021

\section{References}

1. Jain VK. Atlantoaxial dislocation. Neurol India. 2012;60(1):9-17.

2. Salunke P, Sharma M, Sodhi HB, Mukherjee KK, Khandelwal NK. Congenital atlantoaxial dislocation: a dynamic process and role of facets in irreducibility. J Neurosurg Spine. 2011;15(6):678-85.

3. Salunke P, Sahoo SK, Futane S, Deepak AN, Khandelwal NK. "Atlas shrugged": congenital lateral angular irreducible atlantoaxial dislocation: a case series of complex variant and its management. Eur Spine J. 2016;25(4):1098-108.

4. Salunke P, Sahoo SK, Deepak AN, Khandelwal NK. Redefining congenital atlantoaxial dislocation: objective assessment in each plane before and after operation. World Neurosurg. 2016:95:156-64.

5. Lee SC, Lui TN, Lee ST. Atlantoaxial rotatory subluxation in skeletally immature patients. Br J Neurosurg. 2002;16(2):154-7.

6. Xu J, Yin Q, Xia H, Wu Z, Ma X, Zhang K, Wang Z, Yang J, Ai F, Wang J, Liu J, Mai X. New clinical classification system for atlantoaxial dislocation. Orthopedics. 2013:36(1):e95-100.

7. Wang S, Wang C, Yan M, Zhou H, Dang G. Novel surgical classification and treatment strategy for atlantoaxial dislocations. Spine. 2013;38(21):E1348-56.

8. Liu J, Zhu LJ, Jiang EZ, Bao XG, Hu B, Niu DY, Xu GH. C1-C2 pedicle screw fixation for adolescent with os odontoideum associated atlantoaxial dislocation and a compound reduction technique for irreducible atlantoaxial dislocation. Chin Med J. 2019;132(10):1253-6.

9. Salunke P, Sahoo S, Khandelwal NK, Ghuman MS. Technique for direct posterior reduction in irreducible atlantoaxial dislocation: multi-planar realignment of C1-2. Clin Neurol Neurosurg. 2015;131:47-53.

10. Chang-Wei L, Wei L, Zhen-Sheng M, Yan-Wu L, Long B, Nan Z. Posterior rotating rod reduction strategy for irreducible atlantoaxial subluxations with congenital odontoid aplasia. Spine (Phila Pa 1976). 2010;35(23):2064-70.

11. Wang C, Yan M, Zhou HT, Wang SL, Dang GT. Open reduction of irreducible atlantoaxial dislocation by transoral anterior atlantoaxial release and posterior internal fixation. Spine (Phila Pa 1976). 2006:31(11):E306-13.

12. Hao DJ, He BR, Wu QN. One-stage anterior release and reduction with posterior fusion for treatment of irreducible atlantoaxial dislocation. Orthop Surg. 2009;1(4):305-10.

13. Jain VK, Mittal P, Banerji D, Behari S, Acharya R, Chhabra DK. Posterior occipitoaxial fusion for atlantoaxial dislocation associated with occipitalized atlas. J Neurosurg. 1996;84(4):559-64.

14. Sakou T, Morizono Y, Morimoto N. Transoral atlantoaxial anterior decompression and fusion. Clin Orthop Relat Res. 1984;187:134-8.

15. Subin B, Liu JF, Marshall GJ, Huang HY, Ou JH, Xu GZ. Transoral anterior decompression and fusion of chronic irreducible atlantoaxial dislocation with spinal cord compression. Spine (Phila Pa 1976). 1995;20(11):1233-40.
16. Yin Q, Ai F, Zhang K, Chang Y, Xia H, Wu Z, Quan R, Mai X, Liu J. Irreducible anterior atlantoaxial dislocation: one-stage treatment with a transoral atlantoaxialreduction plate fixation and fusion. Report of 5 cases and review of the literature. Spine (Phila Pa 1976). 2005;30(13):E375-81.

17. Wu YS, Chi YL, Wang XY, Xu HZ, Lin Y, Mao FM, Huang QS, Ni WF. Microendoscopic anterior approach for irreducible atlantoaxial dislocation: surgical techniques and preliminary results. J Spinal Disord Tech. 2010;23(2):113-20.

18. Jun BY. Anatomic study for ideal and safe posterior C1-C2 transarticular screw fixation. Spine (Phila Pa 1976). 1998;23(15):1703-7.

19. Hoh DJ, Liu CY, Wang MY. A radiographic computed tomography-based study to determine the ideal entry point, trajectory, and length for safe fixation using C-2 pars interarticularis screws. J Neurosurg Spine. 2010;12(6):602-12

20. Nitising A, Jetjumnong C, Tisavipat N, Nantaaree S. Posterior C1-C2 fusion using $\mathrm{C} 1$ lateral mass and $\mathrm{C} 2$ pars screw with rod fixation: techniques and outcomes. J Med Assoc Thai. 2011;94(7):794-800.

21. Tang C, Li GZ, Liao YH, Tang Q, Ma F, Wang Q, Zhong DJ. Importance of the occipitoaxial angle and posterior occipitocervical angle in occipitocervical fusion. Orthop Surg. 2019;11(6):1054-63.

22. Shao J, Gao Y, Gao K, Yu Z. Comparison of imaging parameters pre- and post-reductive procedure for atlantoaxial dislocation via posterior fixation using pedicle screw and rod: a cross-sectional study. BMC Musculoskelet Disord. 2019;20(1):451.

23. Richter M, Schmidt R, Claes L, Puhl W, Wilke HJ. Posterior atlantoaxial fixation: biomechanical in vitro comparison of six different techniques. Spine. 2002:27(16):1724-32

24. Salunke P, Sahoo SK, Deepak AN, Ghuman MS, Khandelwal NK. Comprehensive drilling of the $\mathrm{C} 1-2$ facets to achieve direct posterior reduction in irreducible atlantoaxial dislocation. J Neurosurg Spine. 2015:23(3):294-302.

25. Dmitriev AE, Lehman RA, Helgeson MD, Sasso RC, Kuhns C, Riew DK. Acute and long-term stability of atlantoaxial fixation methods: a biomechanical comparison of pars, pedicle, and intralaminar fixation in an intact and odontoid fracture model. Spine. 2009;34(4):365-70.

26. Yoshida M, Neo M, Fujibayashi S, Nakamura T. Comparison of the anatomical risk for vertebral artery injury associated with the C2-pedicle screw and atlantoaxial transarticular screw. Spine. 2006;31(15):E513-7.

27. Mandel IM, Kambach BJ, Petersilge CA, Johnstone B, Yoo JU. Morphologic considerations of $\mathrm{C} 2$ isthmus dimensions for the placement of transarticular screws. Spine. 2000;25(12):1542-7.

28. Salunke P, Sahoo SK, Savardekar A, Ghuman M, Khandelwal NK. Factors influencing feasibility of direct posterior reduction in irreducible traumatic atlantoaxialdislocation secondary to isolated odontoid fracture. $\mathrm{Br} J$ Neurosurg. 2015;29(4):513-9.

29. Neo M, Fujibayashi S, Miyata M, Takemoto M, Nakamura T. Vertebral artery injury during cervical spine surgery: a survey of more than 5600 operations. Spine. 2008;33(7):779-85.

30. Salunke $P$, Singh A, Karthigeyan M. Technique of C2 subfacetal screw in patients with high-riding vertebral artery. World Neurosurg. 2020;144:59.

\section{Publisher's Note}

Springer Nature remains neutral with regard to jurisdictional claims in published maps and institutional affiliations. 